\title{
Time-Resolved Fluorescence Immunochromatography Assay (TRFICA) for Aflatoxin: Aiming at Increasing Strip Method Sensitivity
}

\author{
Hui Li ${ }^{1,2,3,4,5}$, Du Wang ${ }^{5}$, Xiaoqian Tang ${ }^{5}$, Wen Zhang ${ }^{5}$, Qi Zhang ${ }^{1,2,3,4,5 *}$ and Peiwu Li ${ }^{1,2,3,4,5}$ \\ ${ }^{1}$ Oil Crops Research Institute, Chinese Academy of Agricultural Sciences, Wuhan, China, ${ }^{2}$ Key Laboratory of Biology \\ and Genetic Improvement of Oil Crops, Ministry of Agriculture, Wuhan, China, ${ }^{3}$ Laboratory of Quality \& Safety Risk \\ Assessment for Oilseed Products (Wuhan), Ministry of Agriculture, Wuhan, China, ${ }^{4}$ Key Laboratory of Detection \\ for Mycotoxins, Ministry of Agriculture, Wuhan, China, ${ }^{5}$ Quality Inspection \& Test Center for Oilseed Products, Ministry \\ of Agriculture, Wuhan, China
}

\section{OPEN ACCESS}

Edited by: Javier Carballo,

University of Vigo, Spain

Reviewed by:

Shihua Wang,

Fujian Agriculture and Forestry

University, China

Fuguo Xing,

Institute of Food Science and Technology (CAAS), China

*Correspondence: Qi Zhang

zhangqi521x@126.com

Specialty section: This article was submitted to

Food Microbiology, a section of the journal

Frontiers in Microbiology

Received: 13 January 2020 Accepted: 24 March 2020 Published: 06 May 2020

Citation:

Li H, Wang D, Tang X, Zhang W, Zhang $Q$ and Li P (2020)

Time-Resolved Fluorescence Immunochromatography Assay

(TRFICA) for Aflatoxin: Aiming at Increasing Strip Method Sensitivity.

Front. Microbiol. 11:676. doi: 10.3389/fmicb.2020.00676
Aflatoxin is the most harmful mycotoxin that is ubiquitous in foods and agro-products. Because of its high toxicity, maximum admissible levels of aflatoxins (AF) is regulated worldwide, and monitoring of their occurrence in several commodities is mandatory for assuring food safety and consumers' health. Considering that the strip method is very simple and convenient for users, in order to enhance strip assay's sensitivity, a lot of time-resolved fluorescence immunochromatography assays (TRFICAs) were developed recently with increasing several times of assay sensitivity compared with traditional gold nanoparticle-based strip assay (GNP-SA). This review briefly describes the newly developed TRFICA for aflatoxin determination, including TRFICA for aflatoxin $B_{1}\left(A_{F B}\right)$ detection, TRFICA for aflatoxin $M_{1}\left(A_{F} M_{1}\right)$ detection, TRFICA for total aflatoxins $\left(A F B_{1}+B_{2}+G_{1}+G_{2}\right.$ ) detection and the latest identification-nanobodybased TRFICA for aflatoxin detection. The application of TRFICA for aflatoxin detection in different agro-products is also concluded in this review. Reasonably, TRFICA has been becoming one of the most important tool for monitoring aflatoxin in foods and agro-products.

Keywords: time-resolved fluorescence immunochromatography assay (TRFICA), sensitivity, aflatoxin, nanobody, application

\section{INTRODUCTION}

Aflatoxin, a group of highly toxic second metabolites from some Aspergillus species such as Aspergillus flavus and Aspergillus paraticus, has still been threatening human health worldwide and the sustainable and high-quality development of modern agriculture industry (Danesh et al., 2018). Aflatoxin caused lots of serious events in the history. In 1960s, aflatoxin was found from the contaminated feeds that caused "turkey event" (Blout, 1961). In 1974, an outbreak of aflatoxininduced hepatitis occurred in about 200 villages in western India, with maize as the staple food, and in the event, there were 397 patients infected, among which 106 patients died (Krishnamachari et al., 1975; Pitt, 2000). In 2004-2005, Kenya witnessed the largest outbreak of aflatoxin poisoning 
until now, with more than 1,000 people poisoned and 125 deaths, and the "culprit" was eventually identified as aflatoxincontaminated maize (Williams et al., 2004; Muture and Ogana, 2005). As reported in China in 2005, the positive rate of aflatoxin $\mathrm{M}_{1}\left(\mathrm{AFM}_{1}\right)$ in urine of 300 volunteers from some universities in Guangzhou was as high as 47\%. Aflatoxin contamination also resulted in huge economic losses. During the past decade, the ratio of export trade notification from EU caused by aflatoxin exceeded the corresponding government's maximum limit, close to $30 \%$. Even in developed country like the United States, aflatoxin caused over 225 million dollars loss per year (Robens and Cardwell, 2003).

Sensitive detection method is the key tool for monitoring aflatoxin contamination and preventing contaminated foods far away from table. Aflatoxin, belonging to natural contaminants, was found in many agricultural products (maize, rice, groundnut, etc.), foods (edible plant oil, milk, meat, etc.), and feeds and may occur in the steps of planting field, harvest, transport, storage, process, and even circulation of commodities (Wang B. et al., 2016; Zhao et al., 2018). Therefore, it is most important to find the contamination on time.

As is known, a lot of analytical methods for aflatoxin detection have been developed. Instrumental methods, such as high-performance liquid chromatography (HPLC) with fluorescence detector (Koc et al., 2009; Sheijooni-Fumani et al., 2011; Kong et al., 2013) and ultraperformance liquid chromatography-tandem mass spectrometry (UPLC-MS/MS) (Scholl, 2004; Cervino et al., 2008; Scholl and Groopman, 2008; Deng et al., 2017), may give precise results and especially fit for lab performance but not for on-site detection. However, more and more producers want to use on-site assay methods for monitoring and ensuring their products' quality. Immunoassays have been developed especially for this aim (Kolosova et al., 2006; Tang et al., 2010; Masinde et al., 2013; Lin et al., 2017; Yao et al., 2017; Pan et al., 2018; Wang et al., 2018; Bhardwaj et al., 2019). Among the developed immunoassays, membrane-based strip assay for aflatoxin determination becomes more and more popular, although it was found to have lower sensitivity than ELISA (Wang et al., 2011; Anfossi et al., 2013). As ELISA is still limited to special equipment in laboratories and is time consuming, these make it not suitable for on-site monitoring (Hu et al., 2017).

Considering that the strip method is very simple and convenient for users, recently, many efforts were made for enhancing strip assay's sensitivity. Time-resolved fluorescence immunochromatography assay (TRFICA) is one of the important new methods (Rundstrom et al., 2007), which was reported to increase several times of the detection sensitivity compared with that of the traditional gold nanoparticle-based strip assay (GNP-SA). Expensive time-resolved fluorescence detector was ever thought as the bottleneck for TRFICA technology (Liu et al., 2016). During the past 5 years, with the development of portable TRFICA reader, the TRFICA strip has been enhanced quickly and even occurred in the market.

Therefore, we here first made a review for the newly developed analytical technology: TRFICA for aflatoxin detection.

\section{PRINCIPLE}

TRFICA combines the advantage of time-resolved fluorescence immunoassay (TRFIA) and chromatography, labeling the lanthanide-chelate-embedded nanoparticles or microbeads with antibodies or protein, which are captured in the detection area by the principle of chromatography (Ye et al., 2004; Xia et al., 2009). Lanthanide chelates exhibit highly desirable fluorescence characteristics: (1) long fluorescence lifetime $\left(\mathrm{Eu}^{3+}\right.$ has a lifetime on the order of millisecond, which is several orders of magnitude longer than that of the non-specific background autofluorescence) (Karhunen et al., 2011); (2) wide excitation spectrum and narrow and sharp emission spectrum (Hemmilä, 1995; Matsumoto and Yuan, 2003); and (3) a large Stokes shift (200-300 nm) (Huhtinen et al., 2005; Binnemans, 2009; Ouyang et al., 2011), with improved spatial resolution. Lanthanide chelates were embedded into microbeads to increase fluorescence intensity (Harma et al., 2001; Huhtinen et al., 2004; Kokko et al., 2007), which effectively resolve the limitation of conventional dissociation-enhanced lanthanide fluorescence immunoassay used in liquid phase only (Xia et al., 2013; Xu et al., 2013; Zhang et al., 2014). What is more, through wave resolution and time-delay technique, TRFICA can be used for quantitative detection with high sensitivity, wide linear range, and low background.

A sample pad, nitrocellulose membrane sprayed with test and control lines, and absorbent pad are assembled into a TRFICA device (Tang et al., 2015; Wang et al., 2015; Zhang et al., 2015). The liquid sample in the microreaction pool moves from the sample pad, through nitrocellulose membrane, to the absorbent pad through capillary action. In the absence of aflatoxin, the fluorescent lanthanide microbead-labeled antibodies react with the immobilized antigen (aflatoxin-protein conjugate) on the test line and secondary antibody on the control line, so two colored lines are observed under ultraviolet illumination. However, when aflatoxin presents in the sample, the aflatoxin-protein conjugate immobilized on the test line competes with the aflatoxin in samples to bind with lanthanide microbead-labeled antibodies. Thus, the fluorescence signal in the test zone is negatively correlated with the concentrations of [Frame1] aflatoxin in the sample, as illustrated in Figure 1.

\section{DEVELOPMENT}

After the first introduction of $\mathrm{Eu}^{3+}$ complexes by Weissman (1942), the TRFICA method was found to be extremely suitable for rapid on-site assay. However, the lack of a portable TRFICA detector greatly limited its wide application in the past few years. In 2015, Wang et al. developed a homemade and portable TRFICA reader for aflatoxin determination. The components of the TRFICA detector are listed as follows: (1) a xenon lamp was used as the excitation source with an excitation wavelength of $365 \pm 10 \mathrm{~nm}$; (2) the emission light was collected at $613 \pm 10 \mathrm{~nm}$ by a photomultiplier tube (PMT) after a 400$\mu$ s delay of the excitation light; (3) the interference band-pass filters were used to obtain the specific excitation and emission 


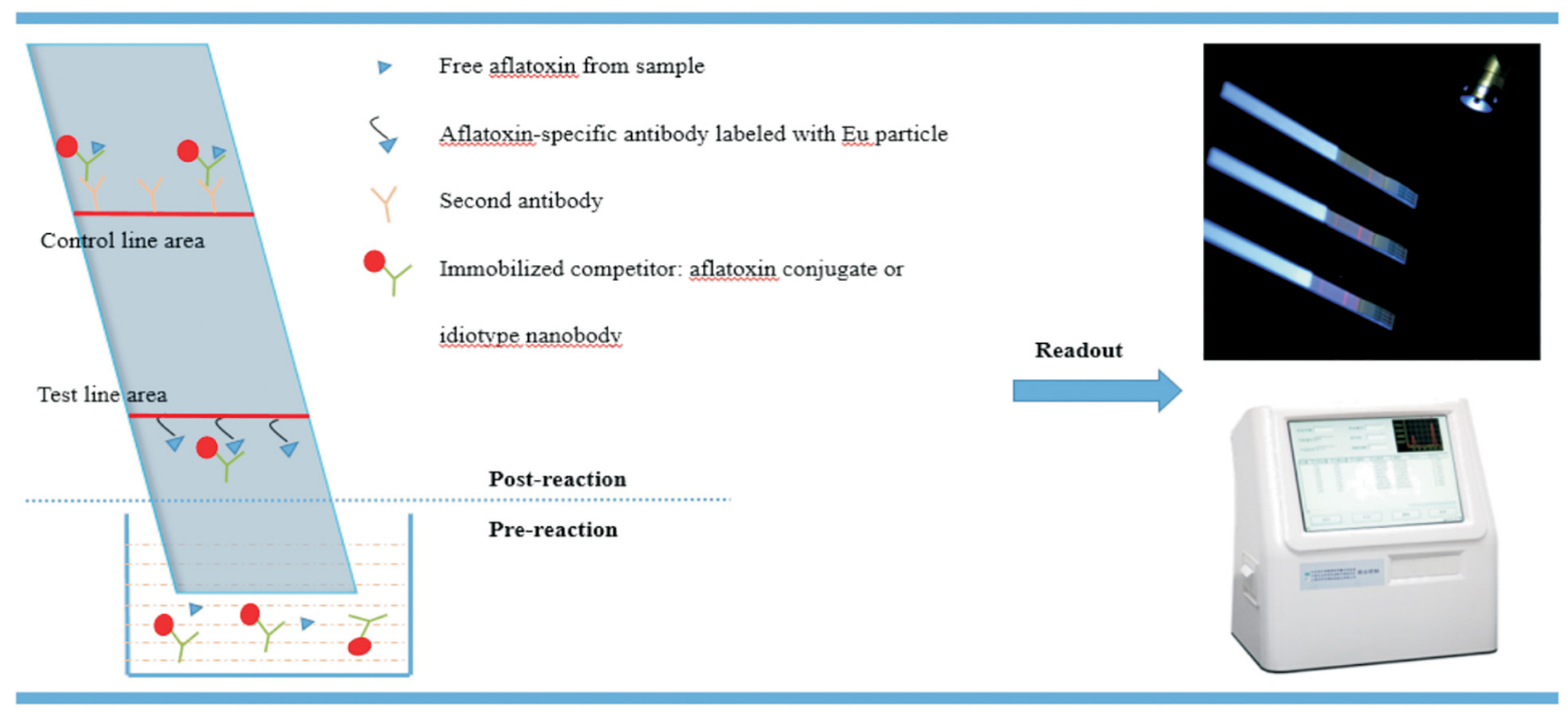

FIGURE 1 | The scheme of time-resolved fluorescence immunochromatography assay (TRFICA) for aflatoxin detection.

bands; (4) the emission signals were processed by a rapid preamplifier-discriminator and pulse counter; and (5) the results were delivered to the readout.

\section{TRFICA for Aflatoxin $\mathbf{B}_{\mathbf{1}}$}

Aflatoxin $\mathrm{B}_{1}\left(\mathrm{AFB}_{1}\right)$ is considered as the most toxic and potent naturally occurring carcinogen, which has been classified as a Group 1 human carcinogen (International Agency for Research on Cancer [IARC], 1993; Streit et al., 2012) mainly targeting liver and lungs (Otim et al., 2005; Turner et al., 2009). It can easily contaminate both food and feed during almost every stages, such as before and after harvest and during storage, transportation, and consumption. Consequently, the study on rapid, effective, and on-site determination of $\mathrm{AFB}_{1}$ in the food chain has attracted tremendous efforts in the past few years, as indicated in Table 1. Zhang et al. developed a portable TRFICA for the sensitive determination of $\mathrm{AFB}_{1}$ (Zhang et al., 2015). First, they fabricated a TRFICA strip. Ovalbumin (OVA) [2\% $(w / v)]$ was used to block the sample pad in order to prevent nonspecific adsorption. On the nitrocellulose membrane, the test and control lines were coated with $\mathrm{AFB}_{1}$-bovine serum albumin $\left(\mathrm{AFB}_{1}-\mathrm{BSA}\right)$ and immunoglobulin $\mathrm{G}(\mathrm{IgG})$, respectively. The distance between the test and control lines was set as $5 \mathrm{~mm}$, so an effective detection zone could be obtained. The sample pad, nitrocellulose membrane, and absorbent pad were assembled onto a plastic scale board in turn and then cut into TRFICA strips with a width and length of 4 and $60 \mathrm{~mm}$, respectively. During the analysis process, free $\mathrm{AFB}_{1}$ and the monoclonal antibody against $\mathrm{AFB}_{1}$ (anti- $\mathrm{AFB}_{1} \mathrm{mAb}$ )-conjugated fluorescent microbeads $\left(\mathrm{Eu}^{3+}\right)$ were mixed in a reaction pool first and then laterally flowed through the TRFICA strip via capillary action. After specific binding interaction of aflatoxin-antiaflatoxin $\mathrm{mAb}$ and antiaflatoxin mAb-IgG, the detection results based on the fluorescence intensity of the test and control lines could be read out in $6 \mathrm{~min}$ using the proposed TRFICA detector. TRFICA exhibited a magnified positive signal with low signal/noise ratio due to the absence of background interference fluorescence and scattering light. This platform demonstrated a wider dynamic range from 0.2 to $60 \mu \mathrm{g} / \mathrm{kg}$, with a lower limit of detection (LOD) from 0.06 to $0.12 \mu \mathrm{g} / \mathrm{kg}$ (12 times diluted sample, be converted to $0.005-0.01 \mathrm{ng} / \mathrm{ml}$ ). The detection sensitivity was increased by two orders of magnitude than that of the competitive ELISA developed by Kolosova et al. for $\mathrm{AFB}_{1}$ detection with an $\mathrm{IC}_{50}$ value of $0.62 \mathrm{ng} / \mathrm{ml}$ (Kolosova et al., 2006). Compared with the

TABLE 1 | A list of time-resolved fluorescence immunochromatography assay (TRFICA) for aflatoxin detection in different samples.

\begin{tabular}{|c|c|c|c|c|c|}
\hline Samples & Analyte & LOD $(\mu \mathrm{g} / \mathrm{kg})$ & Linear range $(\mu \mathrm{g} / \mathbf{k g})$ & Recovery (\%) & References \\
\hline Feed & AFB1 & 0.06 & $0.2-60$ & $80.5-116.7$ & Zhang et al., 2015 \\
\hline Soybean sauce & AFB1 & 0.1 & $0.3-10.0$ & $87.2-114.3$ & Wang D. et al., 2016 \\
\hline Maize & AFB1 & 0.05 & $0.13-4.54$ & $72.6-106.6$ & Tang et al., 2017 \\
\hline Chinese herbal medicines & AFB1 & 0.60 & $0.60-3.92$ & $73-95 \%$ & Sun et al., 2018 \\
\hline Peanut & AFB1 & 0.18 & $0.48-20$ & $83.24-110.80$ & Wang et al., 2019 \\
\hline Milk & AFM1 & 0.009 & $0.02-0.4$ & $88.7-105.0 \%$ & Li et al., 2018 \\
\hline Feed & $\mathrm{AFB} 1+\mathrm{B} 2+\mathrm{G} 1+\mathrm{G} 2$ & 0.16 & $0.48-30.0$ & $83.9-113.9$ & Wang et al., 2015 \\
\hline
\end{tabular}


previously developed GNP-SA for $\mathrm{AFB}_{1}$ with a visual detection limit (VDL) of $1 \mathrm{ng} / \mathrm{ml}$ (Zhang et al., 2011a), the detection sensitivity was also greatly improved.

\section{TRFICA for AFM}

Aflatoxin $\mathrm{M}_{1}$, which is converted by $\mathrm{AFB}_{1}$ through hydroxylation under liver cytochrome P450 catalysis, is usually excreted from lactating animals that ingest feed contaminated with $\mathrm{AFB}_{1}$. It has been classified as a group $2 \mathrm{~B}$ human carcinogen by the International Agency for Research on Cancer (International Agency for Research on Cancer [IARC], 1993). Aflatoxin $\mathrm{M}_{1}$ can be extensively found in milk and dairy products in both developing and developed countries, causing great threat to consumers' health. Thus, there is an urgent need to develop a rapid and sensitive detection method for $\mathrm{AFM}_{1}$ in milk. Tang et al. (2015) developed a highly sensitive TRFICA to detect $\mathrm{AFM}_{1}$ in milk. The test line was coated with $\mathrm{AFM}_{1}-\mathrm{BSA}$ conjugate, and the control line was coated with the goat antirabbit IgG on the nitrocellulose membrane. The absorbent pad, nitrocellulose membrane, and the glass fiber sample pad were then assembled and cut into $4 \mathrm{~mm} \times 60 \mathrm{~mm}$ TRFICA strips. The anti-AFM $1 \mathrm{mAb}$ 2C9 exhibited high affinity to $\mathrm{AFM}_{1}$ with an affinity constant of $1.74 \times 10^{9} \mathrm{l} / \mathrm{mol}$. Under the competitive ELISA format, its $\mathrm{IC}_{50}$ reached (50\% inhibition concentration of $\mathrm{AFM}_{1}$ ) $0.067 \mathrm{ng} / \mathrm{ml}$, and the cross-reactivity to $\mathrm{AFB}_{1}, \mathrm{~B}_{2}, \mathrm{G}_{1}$, and $\mathrm{G}_{2}$ was $<0.1 \%$. When anti-AFM 1 mAb 2C9 was used in this TRFICA with a competitive format, the detection sensitivity for $\mathrm{AFM}_{1}$ was $0.03 \mathrm{ng} / \mathrm{ml}$. According to the previously reported GNP-SA, which exhibited a VDL of $0.3 \mathrm{ng} / \mathrm{ml}$ for $\mathrm{AFM}_{1}$ (Zhang et al., 2012), the detection limit was enhanced an order of magnitude.

\section{TRFICA for Total Aflatoxins $\left(A F B_{1}+B_{2}+G_{1}+G_{2}\right)$}

Aflatoxins (AF), including $\mathrm{AFB}_{1}, \mathrm{AFB}_{2}, \mathrm{AFG}_{1}$, and $\mathrm{AFG}_{2}$, can occur in a wide range of commodities, such as cereals, tree nuts, and spices. They cause great concern in the globe due to its heavy threat such as teratogenic, mutation, and cancer to human being health. In order to avoid human exposure to AF, strict limits have been set up by international government agencies. Therefore, it is urgent to develop rapid and sensitive detection methods for AF monitoring in agro-products. Wang et al. (2015) developed a TRFICA for highly sensitive total aflatoxin detection. The $\mathrm{AFB}_{1}$-conjugated $\mathrm{BSA}$ and rabbit antimouse IgG were coated on the nitrocellulose membrane as a test line and a control line, respectively. The TRFICA strips were made in a width and length of 4.5 and $70 \mathrm{~mm}$. Antiaflatoxin $\mathrm{mAb}_{4 \mathrm{~F} 12}$ was homemade and purified with a protein $G$ immunoaffinity column before use. Its cross-reactivity toward $\mathrm{AFB}_{1}, \mathrm{AFB}_{2}, \mathrm{AFG}_{1}$, and $\mathrm{AFG}_{2}$ were $100,90.1,84.6$, and $20.7 \%$, respectively. A wide dynamic range from 0.48 to $30.0 \mu \mathrm{g} / \mathrm{kg}$ with a LOD of $0.16 \mu \mathrm{g} / \mathrm{kg}$ (40 times diluted sample, be converted to $0.004 \mathrm{ng} / \mathrm{ml}$ ) was obtained by this TRFICA for total aflatoxin detection. The detection sensitivity is one order of magnitude higher than that of the GNP-SA for total aflatoxin detection with VDLs from 0.03 to $0.25 \mathrm{ng} / \mathrm{ml}$ reported by Zhang et al. (2011b). The detection sensitivity was also higher than that of the ELISA developed by $\mathrm{Li}$ et al. for aflatoxin detection with a LOD of 0.06-0.09 $\mathrm{ng} / \mathrm{ml}$ (Li et al., 2009).

\section{Idiotype Nanobody-Based TRFICA for Aflatoxin}

As is known to all, antibody plays a very important role in immunoassay. In recent years, anti-idiotypic antibodies, also named as anti-idiotypic nanobodies (AIdnbs), which are composed of only heavy chains obtained from camelids, have gained considerable attention due to their unique properties (Muyldermans, 2013; Muyldermans and Lauwereys, 1999; Bazin et al., 2017). They can be prepared in large quantities, and the small size makes them suitable for bioengineering. What is more, the interaction between AIdnbs and its antigen changes from a majority of side-chain contacts to main-chain contact, which makes them useful in molecular mimicry. They also exhibited high solubility and chemical stability compared with traditional mAbs in sample matrix. Combining the unique characteristic of AIdnbs with the advantage of TRFICA, Tang et al. (2017) developed a highly sensitive and green immunoassay for $\mathrm{AFB}_{1}$ detection without the use of toxic traditional antigen. For AIdnb-based TRFICA, phages 2-5 (anti-1C11 nanobody) used as capture antigen and rabbit IgG were coated on the nitrocellulose membrane, respectively. During the TRFICA procedure, $A F B_{1}$ in the sample bound to its specific antibody $1 \mathrm{C} 11$ first. After the capillary action, the competitive reaction between phages $2-5$ and $\mathrm{AFB}_{1}$ toward $\mathrm{mAb} 1 \mathrm{C} 11$ occurred on the test line. Under optimal conditions, AIdnb-TRFICA provided a quantitative relationship ranging from 0.13 to $4.54 \mathrm{ng} / \mathrm{ml}$ for $\mathrm{AFB}_{1}$, with a LOD of $0.05 \mathrm{ng} / \mathrm{ml}$ in the buffer solution.

\section{MAIN APPLICATIONS}

The TRFICA offers many advantages: (1) simple operation, fast analysis, and less time consuming; (2) practicality for on-site use; (3) high accuracy; and (4) good reproducibility and stability. As the fluorescence lifetime of lanthanide chelates is several orders of magnitude longer than that of the background interference fluorescence in agroproducts, it is favorable to collect the fluorescence signal of lanthanide-chelate-embedded microbeads coupled with aflatoxin in the absence of background fluorescence by time delay technique. Therefore, the detection

TABLE 2 | Comparison of the detection sensitivity of time-resolved fluorescence immunochromatography assay (TRFICA) and gold nanoparticle-based strip assay (GNP-SA).

\begin{tabular}{|c|c|c|c|c|}
\hline \multirow[t]{2}{*}{ Analyte } & \multicolumn{2}{|c|}{ LOD (ng/ml) } & \multirow{2}{*}{$\begin{array}{l}\text { Compare results } \\
\text { (enhanced times) }\end{array}$} & \multirow[t]{2}{*}{ References } \\
\hline & TRFICA & GNP-SA & & \\
\hline AFB1 & 0.005 & 1 & $\begin{array}{l}\text { Three orders of } \\
\text { magnitude }\end{array}$ & $\begin{array}{l}\text { Zhang et al., } \\
2011 a, 2015\end{array}$ \\
\hline AFM1 & 0.03 & 0.3 & $\begin{array}{l}\text { One order of } \\
\text { magnitude }\end{array}$ & $\begin{array}{l}\text { Zhang et al., } \\
\text { 2012; Tang } \\
\text { et al., } 2015\end{array}$ \\
\hline $\begin{array}{l}\mathrm{AF} \\
(\mathrm{B} 1+\mathrm{B} 2+ \\
\mathrm{G} 1+\mathrm{G} 2)\end{array}$ & 0.004 & 0.03 & $\begin{array}{l}\text { One order of } \\
\text { magnitude }\end{array}$ & $\begin{array}{l}\text { Zhang et al., } \\
2011 \text { b; Wang } \\
\text { et al., } 2015\end{array}$ \\
\hline
\end{tabular}


sensitivity and reliability are greatly improved in TRFICA. In recent years, TRFICA has been widely used for aflatoxin detection in several kinds of agro-products.

In 2015, Zhang et al. developed a portable TRFICA for sensitive and on-site determination of $\mathrm{AFB}_{1}$ in food and feed samples. This method provided a wide dynamic range of $0.2-$ $60 \mu \mathrm{g} / \mathrm{kg}$ with a LOD from 0.06 to $0.12 \mu \mathrm{g} / \mathrm{kg}$, and good recovery was also obtained in different food and feed sample matrices from 80.5 to $116.7 \%$ (Zhang et al., 2015). A sensitive TRFICA was developed by Wang D. et al. (2016) for the detection of $\mathrm{AFB}_{1}$ in soybean sauce with a dynamic range from 0.3 to $10.0 \mu \mathrm{g} / \mathrm{kg}$ and a LOD of $0.1 \mu \mathrm{g} / \mathrm{kg}$, with recoveries between 87.2 and $114.3 \%$. Tang et al. (2017) developed an AIdnb-based TRFICA for $\mathrm{AFB}_{1}$ detection in maize and its products with a dynamic range from 0.13 to $4.54 \mathrm{ng} / \mathrm{ml}$ and a LOD of $0.05 \mathrm{ng} / \mathrm{ml}$. Good recoveries (72.6-106.6\%) in maize samples were also obtained (Tang et al., 2017). Sun et al. (2018) developed TRFICA for $\mathrm{AFB}_{1}$ detection in Chinese herbal medicines. The established TRFICA showed good linear range from 0.60 to $3.92 \mu \mathrm{g} / \mathrm{kg}$, with a LOD of $0.60 \mu \mathrm{g} / \mathrm{kg}$ in Chinese herbal medicines Semen coicis, Rhizoma dioscoreae, and Platycodon grandiflorus. The average recovery was $73-95 \%$ with a relative standard deviation of $<9.08 \%$ (Sun et al., 2018). Wang et al. (2019) developed a TRFICA for $\mathrm{AFB}_{1}$ detection with a linear detection range of $0.48-20 \mu \mathrm{g} / \mathrm{kg}$ and a LOD of $0.18 \mu \mathrm{g} / \mathrm{kg}$ in peanut. The recovery range was $83.24-110.80 \%$ (Wang et al., 2019). In 2020, a TRFICA for $\mathrm{AFB}_{1}$ detection was established by Chang et al. (2020) with a LOD of $0.04 \mu \mathrm{g} / \mathrm{kg}$ and recoveries ranging from 71.6 to $119.98 \%$ in grains.

Li et al. (2018) developed a TRFICA based on a unique bridgeantibody label to realize on-site detection of $\mathrm{AFM}_{1}$ in milk. Different from the previous reports of TRFICA, the fluorescent Eu nanoparticles were first conjugated with polyclonal antibodies and then with monoclonal antibodies. According to the detection results, the sensitivity of this newly developed TRFICA was greatly improved compared with monoclonal antibodies-labeled fluorescent Eu nanoparticle-based TRFICA. A linear range from 0.02 to $0.4 \mathrm{ng} / \mathrm{ml}$ with a LOD of $0.009 \mathrm{ng} / \mathrm{ml}$ was obtained, and the recoveries ranged from 88.7 to $105.0 \%$ for $\mathrm{AFM}_{1}$.

In 2019, TRFICA was used to detect total AF in corn samples with a calculated limit of quantity of $0.03 \mathrm{ng} / \mathrm{ml}$ (Tang et al., 2019). Wang et al. (2015) developed a TRFICA for total aflatoxin detection in feed samples. It showed a wide dynamic range of $0.48-30.0 \mu \mathrm{g} / \mathrm{kg}$ with a LOD of $0.16 \mu \mathrm{g} / \mathrm{kg}$, and the recoveries

\section{REFERENCES}

Anfossi, L., Baggiani, C., Giovannoli, C., Biagioli, F., D’Arco, G., and Giraudi, G. (2013). Optimization of a lateral flow immunoassay for the ultrasensitive detection of aflatoxin M1 in milk. Anal. Chim. Acta 772, 75-80. doi: 10.1016/j. aca.2013.02.020

Bazin, I., Tria, S. A., Hayat, A., and Marty, J. L. (2017). New biorecognition molecules in biosensor for the detection of toxins. Biosens. Bioelectr. 87, 285-298. doi: 10.1016/j.bios.2016. 06.083

Bhardwaj, H., Pandey, M. K., Rajesh, and Sumana, G. (2019). Electrochemical Aflatoxin B1 immunosensor based on the use of graphene quantum dots and ranged from 83.9 to $113.9 \%$. In 397 feed samples from company and livestock farms throughout China, the detection rate of total $\mathrm{AF}$ was $78.3 \%$, and the concentrations were in the range of $0.50-145.30 \mu \mathrm{g} / \mathrm{kg}$ (Wang et al., 2015).

\section{CONCLUSION}

Aflatoxin is the most harmful mycotoxin that is ubiquitous in foods and agricultural supplies. In order to ensure consumption safety, it is very necessary to develop highly sensitive assay methods for aflatoxin detection. GNP-SA is one of the most simple and popular test method. However, its detection sensitivity is usually unsatisfactory for practical use. In order to improve the detection sensitivity, TRFICA has been developed in recent years. TRFICA for $\mathrm{AFB}_{1}, \mathrm{AFM}_{1}$, and total aflatoxin detection in various kinds of agricultural products has been reported. Compared with the previously reported GNP-SA and ELISA, the detection sensitivity was greatly improved (Table 2). Reasonably, TRFICA has been becoming one of the most important tool for monitoring aflatoxin in foods and agroproducts. In consideration of the advantages of simple operation and practicality for on-site use, TRFICA can be widely used to detect various food contaminants, such as other biotoxins, pesticide, and so on in the future.

\section{AUTHOR CONTRIBUTIONS}

QZ and HL conceived the review and wrote the manuscript. All authors edited, read and approved the final manuscript.

\section{FUNDING}

This work was supported by the Natural Science Foundation of China (2017YFC1200903), the National Key R\&D Program of China (2016YFE0206500), the Natural Science Foundation of China (31801665), the Natural Science Foundation of Hubei Province (2017CFB333), the Basic Scientific Research Operating Expenses of Oil Crops Research Institute, Chinese Academy of Agricultural Sciences (1610172018004), and the Agricultural Science and Technology Innovation Program of Chinese Academy of Agricultural Sciences (CAAS-XTCX201902).

gold nanoparticles. Microchim. Acta 186, 592-603. doi: 10.1007/s00604-0193701-5

Binnemans, K. (2009). Lanthanide-based luminescent hybrid materials. Chem. Rev. 109, 4283-4374. doi: 10.1021/cr8003983

Blout, W. P. (1961). Turkey "X" disease. Turkeys 6, 55-77.

Cervino, C., Asam, S., Knopp, D., Rychlik, M., and Niessner, R. (2008). Use of isotope-labeled aflatoxins for LC-MS/MS stable isotope dilution analysis of foods. J. Agr. Food Chem. 56, 1873-1879. doi: 10.1021/jf073231z

Chang, X. X., Zhang, Y. Q., Liu, H. B., and Tao, X. Q. (2020). A quadruple-label time-resolved fluorescence immunochromatographic assay for simultaneous quantitative determination of three mycotoxins in grains. Anal. Methods 12, 247-254. doi: 10.1039/c9ay02309g 
Danesh, N. M., Bostan, H. B., Abnous, K., Ramezani, M., Youssefi, K., Taghdisi, S. M., et al. (2018). Ultrasensitive detection of aflatoxin B1 and its major metabolite aflatoxin M1 using aptasensors: a review. Trends Anal. Chem. 99, 117-128. doi: 10.1016/j.trac.2017.12.009

Deng, H., Su, X., and Wang, H. (2017). Simultaneous determination of aflatoxin $\mathrm{B} 1$, bisphenol A, and 4-nonylphenol in peanut oils by liquid-liquid extraction combined with solid-phase extraction and ultra-high-performance liquid chromatography-tandem mass spectrometry. Food Anal. Method 11, 13031311. doi: $10.1007 / \mathrm{s} 12161-017-1113-\mathrm{x}$

Harma, H., Soukka, T., and Lovgren, T. (2001). Europium nanoparticles and timeresolved fluorescence for ultrasensitive detection of prostate-specific antigen. Clin. Chem. 47, 561-568. doi: 10.1093/clinchem/47.3.561

Hemmilä, I. (1995). Luminescent lanthanide chelates-a way to more sensitive diagnostic methods. J. Alloys Compd. 225, 480-485. doi: 10.1016/0925-8388(94) 07069-5

Hu, L. M., Luo, K., Xia, J., Xu, G. M., Wu, C. H., Han, J. J., et al. (2017). Advantages of time-resolved fluorescent nanobeads compared with fluorescent submicrospheres, quantum dots, and colloidal gold as label in lateral flow assays for detection of ractopamine. Biosens. Bioelectron. 91, 95-103. doi: 10.1016/j. bios.2016.12.030

Huhtinen, P., Kivelä, M., Kuronen, O., Hagren, V., Takalo, H., and Tenhu, H. (2005). Synthesis, characterization, and application of Eu(III), Tb(III), Sm(III), and Dy(III) lanthanide chelate nanoparticle labels. Anal. Chem. 77, 2643-2648. doi: 10.1021/ac048360i

Huhtinen, P., Soukka, T., Lövgren, T., and Härmä, H. (2004). Immunoassay of total prostate-specific antigen using europium (III) nanoparticle labels and streptavidin-biotin technology. J. Immunol. Methods 294, 111-122. doi: 10. 1016/j.jim.2004.09.002

International Agency for Research on Cancer [IARC] (1993). IARC Monograph on the Evaluation of Carcinogenic Risk To Humans, Vol. 56. Lyon: IARC.

Karhunen, U., Rosenberg, J., Lamminmaki, U., and Soukka, T. (2011). Homogeneous detection of avidin based on switchable lanthanide luminescence. Anal. Chem. 83, 9011-9016. doi: 10.1021/ac2018052

Koc, F., Sunnetci, S., Coskuntuna, A., and Coskuntuna, L. (2009). Determination of aflatoxin B1 contamination of commercial mixed feeds (for dairy cow) by immunoaffinity column using high performance liquid chromatography. Asian J. Chem. 21, 2755-2760.

Kokko, L., Lovgren, T., and Soukka, T. (2007). Europium (III)-chelates embedded in nanoparticles are protected from interfering compounds present in assay media. Anal. Chim. Acta 585, 17-23. doi: 10.1016/j.aca.2006.12.006

Kolosova, A. Y., Shim, W. B., Yang, Z. Y., Eremin, S. A., and Chung, D. H. (2006). Direct competitive ELISA based on a monoclonal antibody for detection of aflatoxin B1. Stabilization of ELISA kit components and application to grain samples. Anal. Bioanal. Chem. 384, 286-294. doi: 10.1007/s00216-005-0103-9

Kong, W. J., Li, J. Y., Qiu, F., Wei, J. H., Xiao, X. H., Zheng, Y. G., et al. (2013). Development of a sensitive and reliable high-performance liquid chromatography method with fluorescence detection for high-throughput analysis of multi-class mycotoxins in coix seed. Anal. Chim. Acta 799, 68-76. doi: 10.1016/j.aca.2013.08.042

Krishnamachari, K. A., Bhat, R. V., Nagarajan, V., and Tilak, T. B. (1975). Investigations into an outbreak of hepatitis in parts of western india. Indian J. Med. Res. 63, 1036-1049.

Li, G. H., Xu, L., Wang, D., Jiang, J., Chen, X. M., Zhang, W., et al. (2018). Onsite ultrasensitive detection paper for multiclass chemical contaminants via universal bridge-antibody labeling: mycotoxin and illegal additives in milk as an example. Anal. Chem. 91, 1968-1973. doi: 10.1021/acs.analchem.8b04290

Li, P. W., Zhang, Q., Zhang, W., Zhang, J. Y., Chen, X. M., Jiang, J., et al. (2009). Development of a class-specific monoclonal antibody-based ELISA for aflatoxins in peanut. Food Chem. 115, 313-317. doi: 10.1016/j.foodchem.2008. 11.052

Lin, Y. X., Zhou, Q., Tang, D. P., Niessner, R., and Knopp, D. (2017). Signalon photoelectrochemical immunoassay for aflatoxin B1 based on enzymatic product-etching $\mathrm{MnO} 2$ nanosheets for dissociation of carbon dots. Anal. Chem. 89, 5637-5645. doi: 10.1021/acs.analchem.7b00942

Liu, J. K., Zhao, J. Q., Petrochenko, P., Zheng, J. W., and Hewlett, I. (2016). Sensitive detection of influenza viruses with Europium nanoparticles on an epoxy silica sol-gel functionalized polycarbonate-polydimethylsiloxane hybrid microchip. Biosens. Bioelectr. 86, 150-155. doi: 10.1016/j.bios.2016.06.044
Masinde, L. A., Sheng, W., Xu, X., Zhang, Y., Yuan, M., Kennedy, I. R., et al. (2013). Colloidal gold based immunochromatographic strip for the simple and sensitive determination of aflatoxin B1 and B2 in corn and rice. Microchim. Acta 180, 921-928. doi: 10.1007/s00604-013-1008-5

Matsumoto, K., and Yuan, J. (2003). "Lanthanide Chelates as fluorescence labels for diagnostics and biotechnology," in Metal Ions in Biological Systems: the Lanthanides and Their Interrelations with Biosystems, ed. H. Sigel (Boca Raton, FL: CRC Press), 40.

Muture, B. N., and Ogana, G. (2005). Aflatoxin levels in maize and maize products during the 2004 food poisoning outbreak in Eastern Province of Kenya. East Afr. Mrd. J. 82, 275-279.

Muyldermans, S. (2013). Nanobodies: natural single-domain antibodies. Annu. Rev. Biochem. 82, 775-797. doi: 10.1146/annurev-biochem-063011-092449

Muyldermans, S., and Lauwereys, M. (1999). Unique single-domain antigen binding fragments derived from naturally occurring camel heavy-chain antibodies. J. Mol. Recogn. 12, 131-140. doi: 10.1002/(SICI)1099-1352(199903/ 04) 12:2<131:: AID-JMR454>3.0.CO;2-M

Otim, M. O., Mukiibi-Muka, G., Christensen, H., and Bisgaard, M. (2005). Aflatoxicosis, infectious bursal disease and immune response to Newcastle disease vaccination in rural chickens. Avian Pathol. 34, 319-323.doi: 10.1080/ 03079450500179327

Ouyang, X. Y., Yu, R. Q., Jin, J. Y., Li, J. S., Yang, R. H., Tan, W. H., et al. (2011). New strategy for label-free and time-resolved luminescent assay of protein: conjugate Eu3+ complex and aptamer-wrapped carbon nanotubes. Anal. Chem. 83, 782-789. doi: 10.1021/ac103087z

Pan, D., Li, G., Hu, H., Xue, H., Zhang, M., Zhu, M., et al. (2018). Direct immunoassay for facile and sensitive detection of small molecule aflatoxin B1 based on nanobody. Chem. Eur J. 24, 9869-9876. doi: 10.1002/chem.201801202

Pitt, J. I. (2000). Toxigenic fungi and mycotoxins. Br. Med. Bull. 56, 184-192. doi: 10.1258/0007142001902888

Robens, J., and Cardwell, K. (2003). The costs of mycotoxin management to the USA: management of Aflatoxins in the United States. J. Toxicol. Toxin Rev. 22, 139-152. doi: 10.1081/txr- 120024089

Rundstrom, G., Jonsson, A., Martensson, O., Mendel-Hartvig, I., and Venge, P. (2007). Lateral flow immunoassay using europium (III) chelate microparticles and time-resolved fluorescence for eosinophils and neutrophils in whole blood. Clin. Chem. 53, 342-348. doi: 10.1373/clinchem.2006.074021

Scholl, P. F. (2004). Development of a quantitative LC-MS method for the analysis of aflatoxin B1 serum albumin adducts. Chem. Res. Toxicol. 17, 1764-1764.

Scholl, P. F., and Groopman, J. D. (2008). Long-term stability of human aflatoxin B1 albumin adducts assessed by isotope dilution mass spectrometry and highperformance liquid chromatography-fluorescence. Cancer Epidemiol. Biomark. Prev. 17, 1436-1439. doi: 10.1158/1055-9965.EPI-07-2926

Sheijooni-Fumani, N., Hassan, J., and Yousefi, S. R. (2011). Determination of aflatoxin B1 in cereals by homogeneous liquid-liquid extraction coupled to high performance liquid chromatography-fluorescence detection. J. Sep. Sci. 34, 1333-1337. doi: 10.1002/jssc.201000882

Streit, E., Schatzmayr, G., Tassis, P., Tzika, E., Marin, D., Taranu, I., et al. (2012). Current situation of mycotoxin contamination and co-occurrence in animal feed-focus on Europe. Toxins 4, 788-809. doi: 10.3390/toxins4100788

Sun, S. J., Zheng, P. M., Zhao, S. J., Liu, H. B., Wang, Z. P., Peng, T., et al. (2018). Time-resolved fluorescent immunochromatographic assay-based on three antibody labels for the simultaneous detection of aflatoxin B1 and zearalenone in Chinese herbal medicines. Food Addit. Contam. Part A Chem. 35, 2434-2442. doi: 10.1080/19440049.2018.1539251

Tang, D., Yu, Y., Niessner, R., Miró, M., and Knopp, D. (2010). Magnetic bead-based fluorescence immunoassay for aflatoxin B1 in food using biofunctionalized rhodamine B-doped silica nanoparticles. Analyst 135, 26612667. doi: 10.1039/c0an00221f

Tang, X. Q., Li, P. W., Zhang, Q., Zhang, Z. W., Zhang, W., and Jiang, J. (2017). Time-resolved fluorescence immunochromatographic assay developed using two idiotypic nanobodies for rapid, quantitative, and simultaneous detection of aflatoxin and zearalenone in maize and its products. Anal. Chem. 89, 11520-11528. doi: 10.1021/acs.analchem.7b02794

Tang, X. Q., Zhang, Q., Zhang, Z. W., Ding, X. X., Jiang, J., Zhang, W., et al. (2019). Rapid, on-site and quantitative paper-based immunoassay platform for concurrent determination of pesticide residues and mycotoxins. Anal. Chim. Acta 1078, 142-150. doi: 10.1016/j.aca.2019.06.015 
Tang, X. Q., Zhang, Z. W., Li, P. W., Zhang, Q., Jiang, J., Wang, D., et al. (2015). Sample-pretreatment-free based high sensitive determination of aflatoxin M1 in raw milk using a time-resolved fluorescent competitive immunochromatographic assay. RSC Adv. 5, 558-564. doi: 10.1039/c4ra12097c

Turner, N. W., Subrahmanyam, S., and Piletsky, S. A. (2009). Analytical methods for determination of mycotoxins: a review. Anal. Chim. Acta 632, 168-180. doi: 10.1016/j.aca.2008.11.010

Wang, B., Chen, Y., Wu, Y., Weng, B., Liu, Y., Lu, Z., et al. (2016). Aptamer induced assembly of fluorescent nitrogen-doped carbon dots on gold nanoparticles for sensitive detection of AFB1. Biosens. Bioelectr. 78, 23-30. doi: 10.1016/j.bios. 2015.11.015

Wang, D., Zhang, Z. W., Li, P. W., Zhang, Q., Ding, X. X., and Zhang, W. (2015). Europium nanospheres-based time-resolved fluorescence for rapid and ultrasensitive determination of total aflatoxin in feed. J. Agric. Food Chem. 63, 10313-10318. doi: 10.1021/acs.jafc.5b03746

Wang, D., Zhang, Z. W., Li, P. W., Zhang, Q., and Zhang, W. (2016). Timeresolved fluorescent immunochromatography of aflatoxin B1 in soybean sauce: a rapid and sensitive quantitative Analysis. Sensors 2016, 1094-1102. doi: 10. 3390/s16071094

Wang, D., Zhu, J. G., Zhang, Z. W., Zhang, Q., Zhang, W., Yu, L., et al. (2019). Simultaneous lateral flow immunoassay for multi-class chemical contaminants in maize and peanut with one-stop sample preparation. Toxins 11, 56-66. doi: 10.3390/toxins11010056

Wang, J. J., Liu, B. H., Hsu, Y. T., and Yu, F. Y. (2011). Sensitive competitive direct enzyme-linked immunosorbent assay and gold nanoparticle immunochromatographic strip for detecting aflatoxin M1 in milk. Food Control 22, 964-969. doi: 10.1016/j.foodcont.2010.12.003

Wang, Y. G., Zhao, G. H., Li, X. J., Liu, L., Cao, W., and Wei, Q. (2018). Electrochemiluminescent competitive immunosensor based on polyethyleneimine capped $\mathrm{SiO} 2$ nanomaterials as labels to release $\mathrm{Ru}(\mathrm{bpy}) 32+$ fixed in $3 \mathrm{D} \mathrm{Cu} / \mathrm{Ni}$ oxalate for the detection of aflatoxin B1. Biosens. Bioelectr. 101, 290-296. doi: 10.1016/j.bios.2017.10.042

Weissman, S. I. (1942). Intramolecular Energy Transfer The fluorescence of complexes of europium. J. Chem. Phys. 10, 214-217. doi: 10.1063/1.1723709

Williams, J. H., Phillips, T. D., Jolly, P. E., Stiles, J. K., Jolly, C. M., and Aggarwal, D. (2004). Human aflatoxicosis in developing countries: a review of toxicology, exposure, potential health consequences, and interventions. Am. J. Clin. Nutr. 80, 1106-1122. doi: 10.1093/ajcn/80.5.1106

Xia, X., Xu, Y., Ke, R., Zhang, H., Zou, M., Yang, W., et al. (2013). A highly sensitive europium nanoparticle-based lateral flow immunoassay for detection of chloramphenicol residue. Anal. Bioanal. Chem. 405, 7541-7544. doi: 10.1007/ s00216-013-7210-9

Xia, X., Xu, Y., Zhao, X., and Li, Q. (2009). Lateral flow immunoassay using europium chelate-loaded silica nanoparticles as labels. Clin. Chem. 55, 179-182. doi: 10.1373/clinchem.2008.114561
Xu, W., Chen, X., Huang, X., Yang, W., Liu, C., Lai, W., et al. (2013). Ru(phen)32+ doped silica nanoparticles based immunochromatographic strip for rapid quantitative detection of beta-agonist residues in swine urine. Talanta 114, 160-166. doi: 10.1016/j.talanta.2013.04.013

Yao, M. W., Wang, L. Y., and Fang, C. Z. (2017). The chemiluminescence immunoassay for aflatoxin B1 based on functionalized magnetic nanoparticles with two strategies of antigen probe immobilization. Luminescence 32, 661-665. doi: 10.1002/bio.3235

Ye, Z. Q., Tan, M. Q., Wang, G. L., and Yuan, J. L. (2004). Preparation, characterization, and time-resolved fluorometric application of silica-coated terbium (III) fluorescent nanoparticles. Anal. Chem. 76, 513-518. doi: 10.1021/ ac030177m

Zhang, D. H., Li, P. W., Yang, Y., Zhang, Q., Zhang, W., Xiao, Z., et al. (2011a). A highly selective immunochromatographic assay for rapid detection of aflatoxin B1. Talanta 2011, 736-742. doi: 10.1016/j.talanta.2011.04.061

Zhang, D. H., Li, P. W., Zhang, Q., and Zhang, W. (2011b). Ultrasensitive nanogold probe-based immunochromatographic assay for simultaneous detection of total aflatoxins in peanuts. Biosens. Bioelectr. 26, 2877-2882. doi: 10.1016/j.bios.2010. 11.031

Zhang, D. H., Li, P. W., Zhang, Q., Yang, Y., Zhang, W., Guan, D., et al. (2012). Extract-free immunochromatographic assay for on-site tests of aflatoxin M1 in milk. Anal. Methods 4, 3307-3313. doi: 10.1039/c2ay25205h

Zhang, F., Zou, M., Chen, Y., Li, J., Wang, Y., Qi, X., et al. (2014). Lanthanidelabeled immunochromatographic strips for the rapid detection of Pantoea stewartii subsp. stewartii. Biosens. Bioelectr. 51, 29-35. doi: 10.1016/j.bios.2013. 06.065

Zhang, Z. W., Tang, X. Q., Wang, D., Zhang, Q., Li, P. W., and Ding, X. X. (2015). Rapid on-site sensing aflatoxin B1 in food and feed via a chromatographic timeresolved fluoroimmunoassay. PLoS One 10:e0123266. doi: 10.1371/journal. pone.0123266

Zhao, M., Wang, P., Guo, Y., Wang, L., Luo, F., Qiu, B., et al. (2018). Detection of aflatoxin B1 in food samples based on target-responsive aptamer-crosslinked hydrogel using a hand held $\mathrm{pH}$ meter as readout. Talanta 176, 34-39. doi: 10.1016/j.talanta.2017.08.006

Conflict of Interest: The authors declare that the research was conducted in the absence of any commercial or financial relationships that could be construed as a potential conflict of interest.

Copyright (c) $2020 \mathrm{Li}$, Wang, Tang, Zhang, Zhang and Li. This is an open-access article distributed under the terms of the Creative Commons Attribution License (CC BY). The use, distribution or reproduction in other forums is permitted, provided the original author(s) and the copyright owner(s) are credited and that the original publication in this journal is cited, in accordance with accepted academic practice. No use, distribution or reproduction is permitted which does not comply with these terms. 